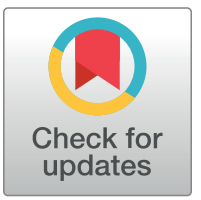

\section{OPENACCESS}

Citation: Chen C-K, Tsai T-H, Lin Y-C, Lin C-C, Hsu S-C, Chung C-Y, et al. (2018) Acceptance of different design exergames in elders. PLOS ONE 13 (7): e0200185. https://doi.org/10.1371/journal. pone. 0200185

Editor: Yih-Kuen Jan, University of Illinois at Urbana-Champaign, UNITED STATES

Received: August 21, 2017

Accepted: June 21, 2018

Published: July 5, 2018

Copyright: @ 2018 Chen et al. This is an open access article distributed under the terms of the Creative Commons Attribution License, which permits unrestricted use, distribution, and reproduction in any medium, provided the original author and source are credited.

Data Availability Statement: All relevant data are within the paper and its Supporting Information files.

Funding: This research was supported by the Chang Gung Medical Foundation, https://www. cgmh.org.tw/eng2002/center_main.htm, grants: CMRPG5B0051-53 (Alice M K Wong), CMPRD3B0031-33 (Chung-Chih Lin), and CMRPG5B0061-63 (Chia-Ying Chung). The funders had no role in study design, data collection and analysis, decision to publish, or preparation of the manuscript.

RESEARCH ARTICLE

\title{
Acceptance of different design exergames in elders
}

\author{
Chih-Kuang Chen ${ }^{1,2 \odot}$, Tsai-Hsuan Tsai ${ }^{30}$, Yin-Chou Lin ${ }^{1,2}$, Chung-Chih Lin ${ }^{2,4}$, Su- \\ Chu Hsu ${ }^{5}$, Chia-Ying Chung ${ }^{1,2}$, Yu-Cheng Pei ${ }^{1,2}$, Alice M. K. Wong ${ }^{1,2 \odot *}$
}

1 Department of Physical Medicine and Rehabilitation, Chang Gung Memorial Hospital, Taoyuan, Taiwan, 2 Healthy Aging Research Center, Chang Gung University, Taoyuan, Taiwan, 3 Department of Industrial Design, Chang Gung University, Taoyuan, Taiwan, 4 Department of Computer Science and Information Engineering, Chang Gung University, Taoyuan, Taiwan, 5 Department of New Media Art, Taipei National University of the Arts, Taipei, Taiwan

๑ These authors contributed equally to this work.

*walice@cgmh.org.tw

\section{Abstract}

For promoting the successful aging of elderly residents of Chang Gung Silver Village in Taiwan, five interactive exergames were developed to promote the well-being of the elderly. The exergames included both physical games and cognitive games, and were implemented using various computer-based technologies in the Chang Gung Silver Village. The exergames were trialed by 39 elderly residents ( 15 male, 24 female; mean age $79.5 \pm 17.5$ years) of Chang Gung Silver Village. Following the trials, the participants were requested to complete a Technology Acceptance Model 2 (TAM2) questionnaire. The results showed that the perceived playfulness and perceived usefulness of the exergames were significantly related to the users' usage behavior and intention to use for both the physical games and the cognitive games. However, a relationship between the output quality of the game and the usage behavior was apparent only in the case of the cognitive exergames. Finally, the impact of social influence on the intention to use and the usage behavior was more pronounced for the physical exergames. Overall, the results revealed that the acceptance of exergames by the elderly depends not so much on the awareness of fun in using the game, but the perceived usefulness of the related physical and cognitive abilities.

\section{Introduction}

According to the WHO's "biopsychosocial model of health", human health comprises the complete state of physical, mental and social well-being, not only the absence of disease and infirmity. Regular exercise has long been proposed as a means of enhancing the physical, mental and social functions of the elderly, thereby reducing the morbidity and mortality inherent in a sedentary lifestyle [1]. The physical benefits of exercise include reducing the risks of obesity, high blood pressure, diabetes, and even cancer [2]. Furthermore, exercise can relieve the symptoms of depression and anxiety, and improve memory and processing speed [3]. Studies have shown that aerobic exercise can also improve decision-making skills [4]. Nevertheless, 
Competing interests: The authors have declared that no competing interests exist. older adults are sometimes reluctant to exercise due to a lack of motivation, social support and company, or a safe and practical environment in which to do so [5].

Exergames, a combination of exercise and computer game, include such commercial products as Nintendo Wii ${ }^{\mathrm{TM}}$ and the XBOX Kinect ${ }^{\mathrm{TM}}$. Exergames have been developing since the late 1980s. They became more commercially known thanks to DDR ${ }^{\mathrm{TM}}$ (Dance Dance Revolution), a 1998 interactive dance mat on which players must move in the direction of visual cues and in time to background music. Exergames became even more popular with the success of Sony Eye Toy (2004), Nintendo Wii ${ }^{\circledR}$ (2006), Wii Fit (2007), PlayStation Move ${ }^{\circledR}$ (2009), and Microsoft XBOX Kinect ${ }^{\mathbb{R}}(2010)$. Kinect ${ }^{\mathrm{TM}}$ is the first exergame system where a camera captures body movements in real time, without the need for worn or handheld devices. Exergame has shown its potential to be a motivating and entertaining factor in assisting in rehabilitation (Rehabilitation Exercise System, IREX ${ }^{\mathrm{TM}}$ ). It's designed to be used by people with motor and cognitive impairments, such as patients who have suffered a stroke or traumatic brain injury, or children with cerebral palsy and learning disability.

In recent years, with advances in technology, exergames have emerged as a brand new interaction system for users, allowing them to exercise within their own homes, or in community settings. Given the specific characteristics of the elderly, many researchers have begun to investigate the potential of using exergames to improve older adults' willingness and attitudes toward exercise. Theng and colleagues [6] assessed the efficacy of the Nintendo Wii in promoting exercise among seniors in Singapore. Bieryla and Dold [7] reported that Wii Fit training older adults could significantly increase their Berg Balance Scale (BBS) than control group. Fu and colleagues [8] developed an exergame based on Nintendo's Wii Fit balance board to reduce the risk of falls among seniors with a history of such events. van Diest and colleagues [9] reviewed thirteen studies found that most of them reported positive results in balance ability after an exergame training period. Whitlock and colleagues [10] investigated the issue of video game usability for older adults and found that age-related changes may negatively affect their capacity to benefit from video games. Gao and Mandryk [11] found that causal exergames can yield acute cognitive benefits, as demonstrated by improved cognitive performance on tests requiring focus and attention. Harris and colleagues [12] suggested that exergames may be an appropriate therapeutic tool for improving balance and postural control in older adults. Venheijden Klompstra and colleagues [13] showed that patients with heart failure exhibited improved balance and cognitive functions after playing exergames. Overall, exergaming appears to have significant potential as an exercise strategy for older adults. Chang Gung Silver Village is a retirement community for people over 60 years of age. It services those residents who are walking and living independently without physical or cognitive impairment. We also provide them with a comprehensive physical examination including fitness, twice a year in our Chang Gung Memorial Hospital. All their physical conditions and chronic illness are supervised. The total number of dwellings in Silver Village is approximately 750, with an age range from 60 to 100 and an average age of approximately 80 years old.

The technology acceptance model (TAM) was first proposed by Davis and colleagues [14] based on the theory of reasoned action (TRA) and the theory of planned behavior (TPB) to assess a user's behavioral intentions toward using new technologies. The TAM theorizes that an individual's behavioral intention to use a system is determined by two beliefs, namely, perceived usefulness (PU) and perceived ease of use (PEOU). However, the original TAM was criticized for ignoring social influence and individual characteristics. Hence, an extension of the TAM, referred to as TAM2, was proposed by Venkatesh and Davis [15] that outlined perceived usefulness and usage intentions as it related to the social influence processes (subjective norms, voluntariness, and image) and cognitive instrumental processes (job relevance, output quality, result demonstrability, and perceived ease of use). In an attempt to integrate the main 
competing user acceptance models, Venkatesh et al. [16] further formulated Unified Theory of Acceptance and Use of Technology (UTAUT). Additionally, a TAM3 recommended by Venkatesh and Bala [17] that combined TAM2 with the model of the determinants of perceived ease of use, that presented a comprehensive nomological network of the determinants of individuals' adoption and use of new technologies. All the aforementioned theories are based on users' perspectives to investigate their acceptance of technological systems and effectively predict and explain their motivations and behaviors.

In recent years, the technology acceptance model (TAM, TAM2) is increasingly being applied in exploring factors that influence the willingness of older adults to use a technology, as well as their perceptions and expectations of the type of technology. For examples, the TAM2 was adopted by Tsai et al. [18] to measure user acceptance and usage of a social platform and received positive feedback from those older residents living in a senior community. With the TAM as a theoretical basis, Xue et al. [19] examined the perceived attitudes and readiness of women aged 50 years or older on adopting a mobile phone-based intervention in Singapore. Wong et al. [20] evaluated the older adults' intention of using an Intelligent Comprehensive Interactive Care (ICIC) System using TAM2. Morevoer, Ramón-Jerónimo [21] explained the Internet use in the older segment, capturing the heterogeneity across gender in the TAM (and TAM2). Furthermore, TAM has also expanded to explore behavior patterns and intentions of older adults from the viewpoint of exergame use. Wüest et al. [22] assessed the usability and effects of an exergame-based balance and gait training program in terms of acceptance, adherence, and attrition among elderly participants by the TAM survey. Cook and Winkler [23] used TAM to explore the usability, ease of use, and enjoyment of the application of virtual worlds by older adults. Also, Ben-Sadoun et al. [24] presented the evaluation of usability and short-term training effects of X-Torp of an action Serious exerGames designed for elderly subjects with normal aging, mild and moderate cognitive impairment with regard to technology acceptance (based on the TAM). As a result, in this study, we invited the elderly residents of Chang Gung Silver Village to try the developed exergames in order to increase their levels of physical activity and improve their physiological conditions. They were also requested to answer the TAM questionnaires which were attached as Supporting Information from S1-S10 Files for these exergames.

\section{Hypothesis development}

According to TAM2, output quality was defined as the tasks that the system was capable of performing and the degree to which those tasks could achieve their goals. This represents how well suited the system is for users in terms of those tasks [15]. The effectiveness of exergame tasks depends on providing a clear, instinctive, and usable interface for users to operate easily from the viewpoint of exercising. Therefore, we defined output quality based on user satisfaction with the interface and users' perceptions of the product's appearance. According to a report by Koufaris' report [25] on the relationship between web connection quality and perceived playfulness, the higher the system quality and information quality, the more likely a user will have more fulfilling and enjoyable shopping experiences. Ahn and colleagues [26] found a positive relationship among system quality, information quality, service quality, and playfulness in online retailing. Therefore, we adopted the quality of user interaction with the system interface as the output quality of the exergame.

A relationship between quality and intention to use has been found in other studies. In the context of banking, O'Cass and Grace [27] found that if a service was evaluated as being of a higher quality, consumers would show more favorable attitudes toward that service brand. Furthermore, in the context of Internet shopping, e-service quality factors positively influence 
consumer attitudes toward a website. A similar result was reported by Carlson and O'Cass [28]. They concluded that with better e-service quality, users would have more positive attitudes towards a website. Accordingly, we put forth hypotheses 1 and 2.

- Hypothesis 1. There is a positive relationship between "Output quality" and "Perceived playfulness."

- Hypothesis 2. There is a positive relationship between "Output quality" and "Usage behavior."

The addition of playfulness is based on research by Moon and Kim's research [29], who found that playfulness is an intrinsic belief or motive that is shaped from an individual's experience in an environment. Perceived playfulness in this study was defined in terms of three dimensions, namely, (1) perception that one's attention is focused on the interaction, (2) curiosity during the interaction, and (3) finding the interaction intrinsically enjoyable. Triandis and colleagues [30] proposed that positive and negative emotions might impact one's behavior. Furthermore, based on Csikszentmihalyi's flow theory [31], in which Csikszentmihalyi defined flow as "the holistic sensation that people feel when they act with total involvement," a positive subjective experience is a critical reason for performing an activity. In Moon and Kim's study, positive relationships were also found between perceived playfulness and attitude toward use, and playfulness and behavioral intention to use [29]. Accordingly, we put forth hypotheses 3 and 4 .

- Hypothesis 3. There is a positive relationship between "Perceived playfulness" and "Intention to use."

- Hypothesis 4. There is a positive relationship between "Perceived playfulness" and "Usage behavior".

Numerous studies have shown the relationship among perceived usefulness and intention to use and usage behavior. According to Kim et al., when users' perceived usefulness of an ecommerce website is higher, they are more likely to have a positive attitude toward using it and intention to reuse it. Furthermore, Ahn et al. showed that perceived usefulness is positively related to attitude and behavioral intention to use online retailing websites [26]. In TAM2, the relationship between perceived usefulness and usage behavior was not included, unlike in TAM. Thus, we investigate the relationship between perceived usefulness and usage behavior, as outlined in hypotheses 5 and 6.

- Hypothesis 5. There is a positive relationship between "Perceived usefulness" and "Usage behavior."

- Hypothesis 6. There is a positive relationship between "Perceived usefulness" and "Intention to use."

In many studies based on either TAM or TAM2, the relationships between perceived ease of use and perceived usefulness and intention to use were strong, given that many studies had shown significant path between those factors. According to Kim and colleagues [32], perceived ease of use is a strong predictor of customers' perceived usefulness and attitude toward the use of eCommerce websites. According to Ahn and colleagues, perceived ease of use positively impacted users' perceived usefulness and attitude toward online retailing websites [26]. Thus, we investigated whether perceived ease of use affects perceived usefulness and intention using hypotheses 7 and 8. 
- Hypothesis 7. There is a positive relationship between "Perceived ease of use" and "Perceived usefulness."

- Hypothesis 8. There is a positive relationship between "Perceived ease of use" and "Usage behavior."

In TAM2, subjective norm and image are both categorized as social influence processes [15]. Subjective norm is defined as "perceived pressures on a person to perform a given behavior and the person's motivation to comply with those pressures" by Fishbein and Ajzen [33]. In the original TRA model, both subjective norms and attitude are related to one's behavioral intention [34]. This was also supported by reports in Psychology Research that subjective norms are important variables that affect behavioral intention [35, 36]. For the relationship between subjective norms and the intention to use, Kim et al. [32] showed that subjective norms positively influence the attitude toward use in the context of ecommerce websites. For image, Moore and Benbasat [37] refer to it as "the degree to which one's use of an innovation is perceived to enhance one's status in one's social system." Although in TAM2, image was hypothesized to influence perceived usefulness, we investigated its relationship with intention to use and usage behavior because both image and subjective norms were seen as social influence factors. Thus, we proposed hypotheses $9,10,11$, and 12 for social influence (image and subjective norm).

- Hypothesis 9. There is a positive relationship between "Image" and "Usage behavior."

- Hypothesis 10. There is a positive relationship between "Image" and "Intention to use."

- Hypothesis 11. There is a positive relationship between "Subjective norm" and "Usage behavior."

- Hypothesis 12. There is a positive relationship between "Subjective norm" and "Intention to use."

\section{Materials and methods}

Before the study began, we applied to the Institutional Review Board (IRB) of the Chang Gung Medical Foundation and received the ethics committee's approval of the study date range, from August 1, 2011 to June 30, 2015; the IRB identifier number is 100-1075B as Supporting Information S11 File. All of the participants were recruited and completed the trials during this time period, and the authors confirm that all related trials for this intervention (exergames) are registered. The ClinicalTrials.gov identifier number is NCT03084107 as Supporting Information S12 File. Before the exergames began, the consent was informed and written by the participants to know that they could discontinue the tests if discomfort developed including dizziness. We provided an assistant for each of the elderly to protect them and prevent injury.

\section{Participants}

Thirty-nine elderly residents (15 male, 24 female) from Chang Gung Silver Village (Taiwan) participated in the study. All of them are walking and living independently without physical or cognitive impairment. In order to avoid diverse subjective discomforts of test subjects from their own physical limitations, elders with neuromuscular or musculoskeletal disease (might have pain or soreness), permanent impairment of cardio-pulmonary function (might be very easy to become fatigue or shortness of breath under the stress of test), poor balance (might be more easy to fall), frailty (might be unable to complete the whole test smoothly), and poor 
vision (might be difficult to interact the wall game) were excluded from this study. The mean age of the participants was $79.5 \pm 17.5$ years. Of the 39 participants, 1 was illiterate, 4 went to elementary school, 7 were senior high school graduates, 22 had a bachelor's degree, and 5 had a graduate degree. In terms of their frequency of computer use, 16 had never used a computer, 1 used one occasionally, 1 used one once a month, 4 used one twice a month, 7 used one once a week, 1 used one twice a week, and 9 used one every day or almost every day.

\section{Developed physical and cognitive exergames}

In Chang Gung Silver Village, we provide an indoor space for exergames where the elderly can exercise and learn. They must first be identified and recorded by a radio-frequency identification (RFID) system in every exergame system. We designed this set of exergames for the elderly according to the guidelines of previous studies, including consideration of age-related changes in decrements in posture, balance, gait, fine motor skills, visual and auditory ability, short term memory, as well as attention and vigilance, to avoid causing any injuries [38]. One of our research staffs demonstrated these exergames and signed the consent form for publication as Supporting Information S13 File; the form stated that "The individual in this manuscript has given written informed consent (as outlined in the PLOS consent form) to publish these case details". The DOI link: http://dx.doi.org/10.17504/protocols.io.k46cyze.

Interactive Wall with Life Memories. The "Interactive Wall with Life Memories" exergame was designed to promote physical activity of the arms and upper body of the elderly, while simultaneously encouraging them to recall and share their life memories with others through the medium of photographs (Fig 1). Using the KINECT wireless sensor, the elderly stand in front of a wall projection, waving their arms to select and watch the photos of their previous activities. It involves a space interactive learning device and community learning, that is, the elderly can participate together to recollect life memories with movements of limbs and body.

Interactive Floor Kick and Play. The "Interactive Floor Kick and Play" game was designed to improve the reaction time and lower limb movement (with or without upper limb movement) in elderly users by responding to sudden changes in a pattern of shapes and images

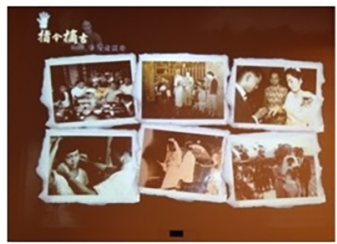

(A)

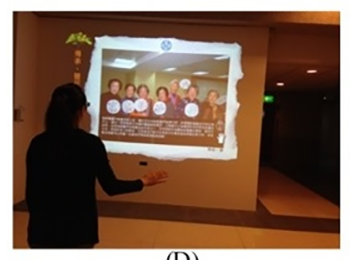

(D)

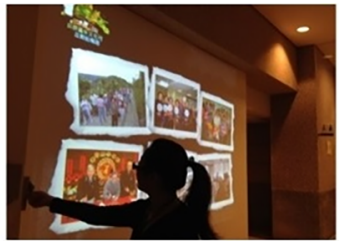

(B)

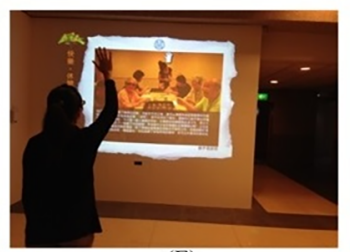

(E)

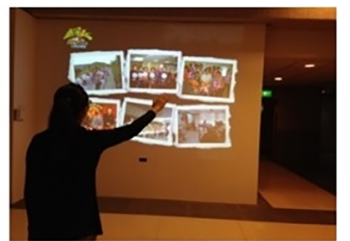

(C)

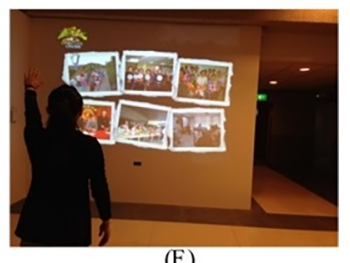

(F)

Fig 1. Interactive Wall with Life Memories. (A) Pictures of life memories are projected onto the wall when user stands in the interaction zone and waves their arms to initiate interaction. (B) Users employ personal RFID cards to identify themselves, and are then presented with a series of self-related photographs in the Silver Village, together with collections of pictures from former times and other educational materials. (C-F) Users employ arm gestures to navigate through various categories of photographs and, for each one, are provided with an audio commentary to facilitate the processes of reminiscence and learning.

https://doi.org/10.1371/journal.pone.0200185.g001 
projected onto the floor (Fig 2). There are three games in this system at different levels of speed. The challenge in this exergame is immediate body movement in response to changes in a portion of the game area. The objective is to enhance the elderly's physical activity and exercise response capabilities.

Ten Pretty Passes of the Bull. The "Ten Pretty Passes of the Bull" game comprises a set of 10 challenges involving a cowboy and a bull presented on a touch-sensitive screen mounted on the wall (Fig 3). The aim of the game is to improve the eye-hand coordination of the users by having users react as quickly as possible to sudden events on the screen, such as a mango falling from a tree or smoke drifting from a kiln. Users are offered a choice of three difficulty levels for each station, namely, simple, ordinary and hard. If the users respond sufficiently quickly to the events they see before them, they are permitted to move onto the next challenge. At the end of the game, the participants are offered the opportunity to send a message to others via an app.

The game is set up such that users are required to take a few steps up a short uphill incline to touch the screen. Thus, in addition to improving users' reaction time of the users, the game also increases their level of physical exertion. Moreover, the inbuilt messaging functionality reinforces social connections among the elderly in the village and their family members and friends in faraway towns.

Interactive Table with Musical Pots. The "Interactive Table with Musical Pots" game involves five pots placed on an interactive table and is designed to help control the metabolic status of the elderly (Fig 4). After RFID authentication, the user is presented (via the table) with a summary of their current metabolic condition in terms of five medical indicators associated with their levels of hypertension, hyperglycemia (diabetes mellitus), dyslipidemia (elevated triglyceride, high density lipoprotein (HDL)), and obesity (abdominal circumference), respectively. Each indicator is associated with a particular pot. Furthermore, each pot contains an electronic circuit and amplification system designed to play a user's favorite song. If a medical indicator is normal, the song within the corresponding pot will play once the pot is picked
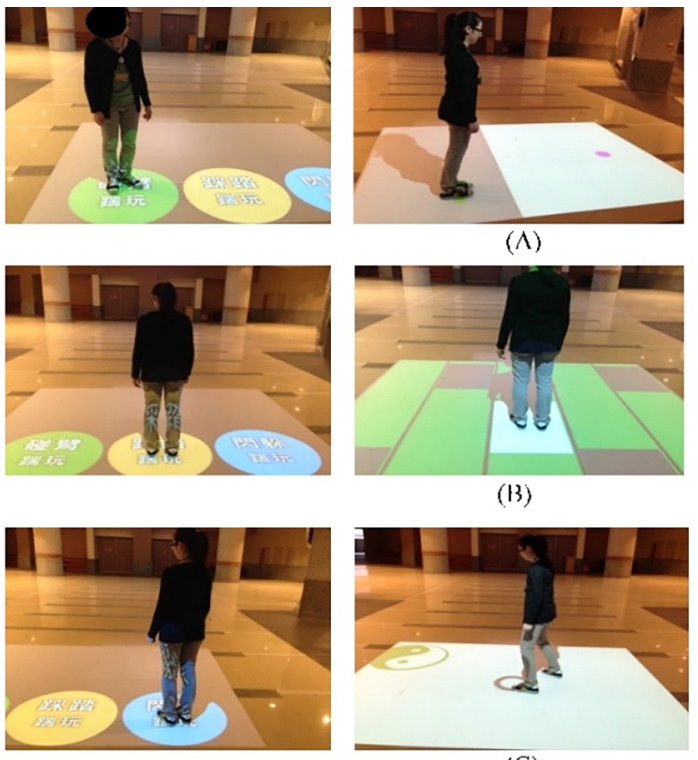

(C)

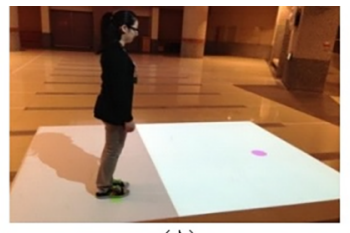

$(\Lambda)$

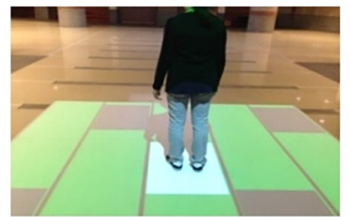

(13)
Fig 2. Interactive Floor Kick and Play. Three different game modes are supported: (A) Touch Arm Kick Play, (B) Stampede Kick Play, and (C) Dodging Kick Play.
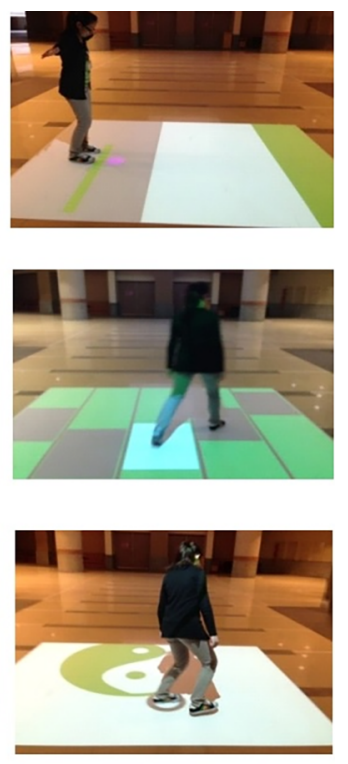

https://doi.org/10.1371/journal.pone.0200185.g002 

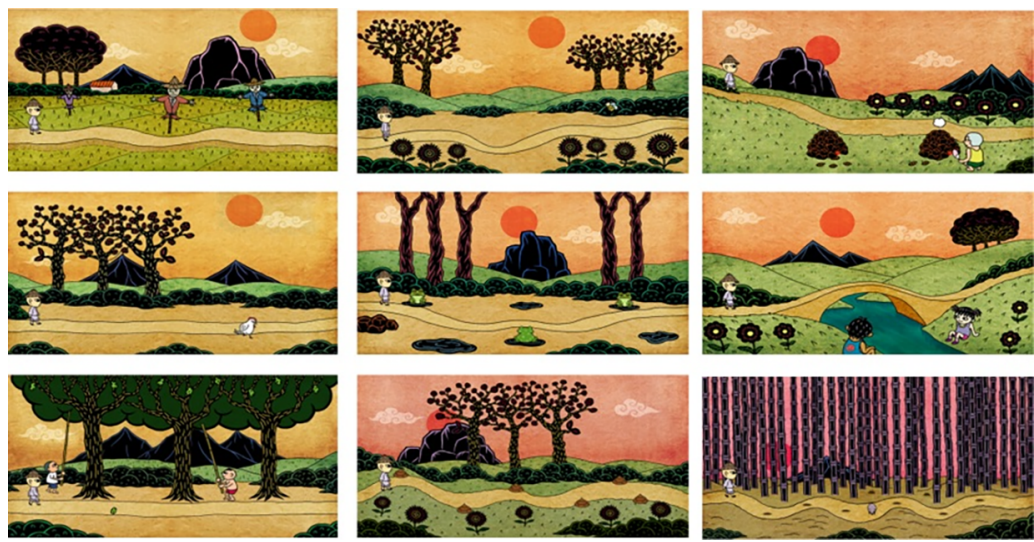

Fig 3. Ten Pretty Pass of the Bull.

https://doi.org/10.1371/journal.pone.0200185.g003

up and brought to the ear. (It will then stop when the pot is returned to the table, as detected by a triaxial accelerometer.) In the event that the indicator is not normal, the song will not play when the pot is picked up. Thus, to listen to all their favorite songs, the users must control their physical condition and undergo regular physiological tests so that their indicators stored on the interactive platform can be updated. These recreational activities can also remind them to take care of their own health situation. If the pots on the table play more songs, the more favorable the health status of the elderly.

Fun Cube. The "Fun Cube" exergame involves a touch-screen computer linked to six cubes showing different pictures, figures, or words (Fig 5). The interactive screen allows the user to choose among many different games, where each game involves the use of the cubes in order to perform such tasks as memory training, sorting, pairing, and basic arithmetic. After each game is completed, the screen displays the user's score for self-comparison purposes or for competition with others. The games are interactive, creative and challenging and are designed to fight memory loss and promote cognitive activity in a fun and user-friendly way.

The five exergames described above can be divided into two different categories, namely, physical ("Interactive Wall with Life Memories," "Interactive Floor Kick and Play," and "Ten Pretty Passes of the Bull") and cognitive ("Interactive Table with Musical Pots" and "Fun Cube").

\section{TAM2 questionnaire}

With the TAM2 as the theoretical foundation of the research model, the experiences of the elderly in using these five exergames were self-reported using a questionnaire based on

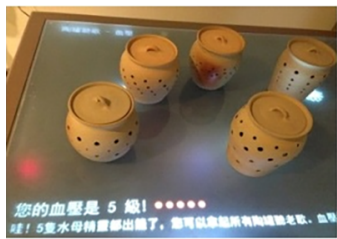

(A)

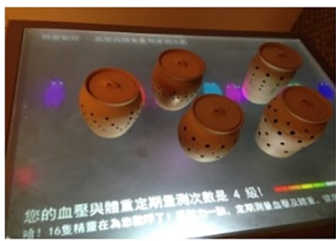

(B)

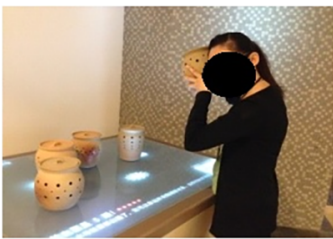

(C)

Fig 4. Interactive Table with Musical Pots. (A-B) After RFID identity authentication, the user is presented with a summary of their metabolic condition (C) If the medical indicator shows normal, the song within the corresponding pot plays once it is brought up to the ear.

https://doi.org/10.1371/journal.pone.0200185.g004 

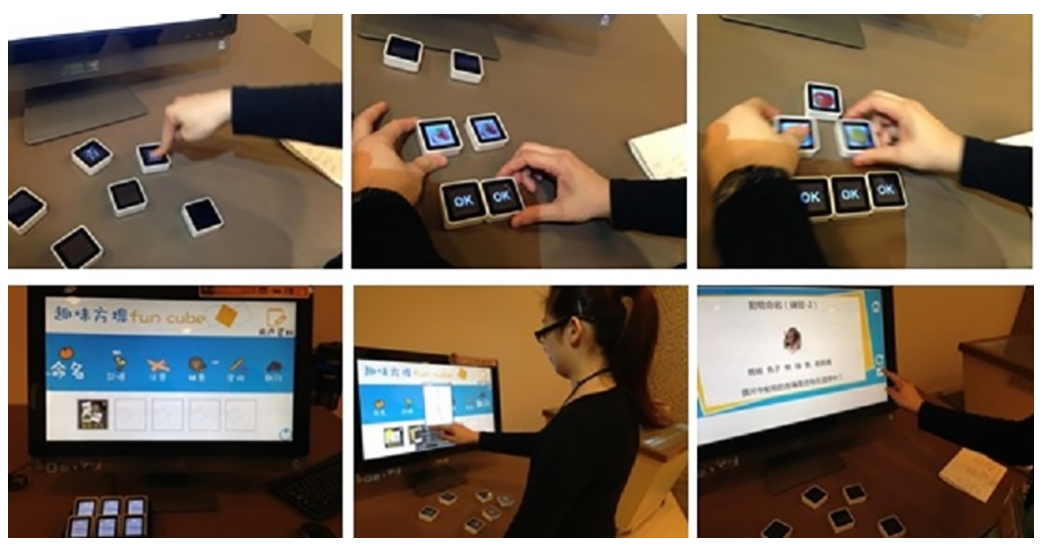

Fig 5. Fun Cube. The Fun cube comprises different types of games (with demonstrations) for such activities as memory training, sorting, pairing, and basic arithmetic.

https://doi.org/10.1371/journal.pone.0200185.g005

Venkatesh and Davis's TAM2 design [15], since this model takes into account 11 variables, with four variables originating from the original TAM questionnaire (i.e. "perceived usefulness", "perceived ease of use", "intention to use" and "usage behavior") and seven additional variables ("voluntariness", "experience", "subjective norm", "image", "job relevance", "output quality" and "result demonstrability"). It it noted that, "voluntariness" and "experience" were defined as moderating variables into TAM2. "voluntariness" was defined to distinguish usage contexts into mandatory and voluntary settings. TAM2 postulated that users' acceptance of a new system could with increasing experience. However, all of the participants were invited to participate and complete the trials in a field experiment setting at Chang Gung silver village; hence, it is not necessary to classify users' usages into voluntary or mandatory contexts. For this reason, voluntariness was excluded from our model. Moreover, even though the elderly participants were labeled experienced or inexperienced computer users in this study, all of the respondents had no previous experiences using exergames. Thus user experience was not considered in the model because it is assumed that older adults were relatively no experienced in exergaming usage. Also, "job relevance" referred to the perception of how applicable the technology is to a user's job. TAM2 theorized that "result demonstrability" as the perception of tangible results due to technology use. With regard to relatedness in the lives of older adults, job relevance and result demonstrability were not included in the model. That is, to achieve a better fit between the model and the present study, its semantics were modified in order to make them more consistent with the presentation of the research topics. Thus irrelevant topics in the question items were deleted, including "voluntariness", "experience", "job relevance", and "result demonstrability". Finally, an additional item of "Perceived playfulness" was added to the model. Each variable was evaluated using a seven-point Likert-type scale with anchors of $1=$ strongly disagree, 2 = disagree, $3=$ somewhat disagree, $4=$ neither agree or disagree, $5=$ somewhat agree, $6=$ agree, $7=$ strongly agree [13].

\section{Statistical analysis}

To avoid older adults' experiences in using computers affecting the results of the structural equation model, a t-test was first performed to examine whether older adults with different computer experiences would answer the questionnaire (each item and each variable as a whole) significantly differently. Participants' responses on both physical and cognitive exergames were analyzed separately. Participants were labeled "non-experienced computer users" if they answered they never used a computer, used one occasionally, or used one once a 
month. Participants were labeled "experienced computer users" if they answered they used computer once every two weeks, once a week, twice a week, or at least once a day. The model used differs from the original TAM2 by adding a perceived playfulness construct as depicted in the hypothesis development section, removing voluntariness, experience, job relevance, and result demonstrability. The structural equation model was tested using Minilab and LISREL. To achieve a better fit between the model and the present study, its semantics were modified in order to make them more consistent with the presentation of the research topics. Moreover, irrelevant topics in the question items were deleted, including "voluntariness", "experience", "job relevance", and "result demonstrability". Finally, an additional item of "Perceived playfulness" was added to the model.

The reliability of the individual items with respect to the corresponding constructs was evaluated by means of the Chronbach's Alpha coefficient. In addition, the validity of the questionnaire constructs was evaluated in terms of both the convergent validity and the discriminant validity. Convergent validity refers to the extent to which the measured variables converge with the same construct. Sufficient convergent validity requires that the average variance extracted (AVE) of the latent variables be no less than 0.5 and the latent variable composite reliability (CR) value be greater than 0.7 [13].

\section{Results}

In the first stage of analysis, when playing physical exergames, Table 1 shows the t-test result of physical exergames between experienced and non-experienced computer users on the questionnaire items and variables. There were significant differences between the two groups of participants on perceived usefulness 1 , perceived usefulness 4 , perceived ease of use 1 , image 1 , image 2, perceived ease of use, and image; there were no significant differences on rest of the questionnaire items and variables. Unlike in the physical exergames, no significant differences were found between experienced and non-experienced computer users on all of the questionnaire items and variables of the cognitive exergams, as shown in Table 2.

\section{Measurement model}

The measurement model was then analyzed for physical and cognitive exergames. First, the Cronbach's Alpha coefficient, which was used to test the reliability of individual items with respect to the corresponding construct variables, as well as the validity of the questionnaire's constructs, was obtained. For both types of exergames, Cronbach's alpha values of all items were higher than 0.7 , and the item-total correlations of each item exceeded 0.3 , thus satisfying the research criteria. For physical exergames, the relevant coefficients of the individual items and the item-total correlations of each dimension were all higher than 0.6 , while those of cognitive exergames were higher than 0.8 , indicating that the instrument had a high degree of reliability and the measured results could be considered very stable. Factor loading was also obtained by conducting confirmatory factor analysis. According to Hair et al., for sample sizes of 100 and 70, factor loading should be at least 0.55 and 0.65 , respectively, for a factor to be considered reliable [39]. The results are shown in Table 3 and Table 4 . Since the sample size of the tests for the three physical exergames was 103, we used the criterion 0.55 and found that all items' factor loading surpassed the threshold, except for PU1 in perceived usefulness, which was close to 0.55 . For the tests of the two cognitive exergames, the sample size was 66; hence, we selected 0.65 as the screening criteria. According to the results, all items' factor loading surpassed the threshold.

Efficiency analysis was conducted using convergent validity and discriminant validity. Convergent validity refers to the extent to which measured variables converge with the same 
Table 1. t-test on physical exergames between experienced and non-experienced computer users on the questionnaire items and variables.

\begin{tabular}{|c|c|c|c|c|c|}
\hline Variable & Experience in using computer & Mean & S.D. & t-value & Significant value \\
\hline \multirow[t]{2}{*}{ Usage behavior 1} & Experience & 6.08 & 0.81 & -0.29 & 0.77 \\
\hline & Non-experience & 6.12 & 0.84 & & \\
\hline \multirow[t]{2}{*}{ Usage behavior 2} & Experience & 6.04 & 0.74 & -0.13 & 0.89 \\
\hline & Non-experience & 6.06 & 1.04 & & \\
\hline \multirow[t]{2}{*}{ Intention to use 1} & Experience & 5.71 & 1.09 & -0.35 & 0.73 \\
\hline & Non-experience & 5.79 & 1.18 & & \\
\hline \multirow[t]{2}{*}{ Intention to use 2} & Experience & 5.69 & 1.08 & -0.69 & 0.50 \\
\hline & Non-experience & 5.83 & 0.98 & & \\
\hline \multirow[t]{2}{*}{ Intention to use 3} & Experience & 5.00 & 1.40 & -1.50 & 0.14 \\
\hline & Non-experience & 5.40 & 1.22 & & \\
\hline \multirow[t]{2}{*}{ Perceived usefulness 1} & Experience & 5.08 & 1.41 & -1.88 & 0.06 \\
\hline & Non-experience & 5.58 & 1.25 & & \\
\hline \multirow[t]{2}{*}{ Perceived usefulness 2} & Experience & 5.48 & 1.44 & -1.08 & 0.28 \\
\hline & Non-experience & 5.77 & 1.24 & & \\
\hline \multirow[t]{2}{*}{ Perceived usefulness 3} & Experience & 5.38 & 1.29 & -0.68 & 0.50 \\
\hline & Non-experience & 5.56 & 1.35 & & \\
\hline \multirow[t]{2}{*}{ Perceived usefulness 4} & Experience & 5.40 & 1.38 & -1.91 & 0.06 \\
\hline & Non-experience & 5.88 & 1.08 & & \\
\hline \multirow[t]{2}{*}{ Perceived ease of use 1} & Experience & 5.81 & 0.89 & 2.58 & 0.01 \\
\hline & Non-experience & 5.08 & 1.75 & & \\
\hline \multirow[t]{2}{*}{ Perceived ease of use 2} & Experience & 5.73 & 0.84 & 1.01 & 0.31 \\
\hline & Non-experience & 5.52 & 1.19 & & \\
\hline \multirow[t]{2}{*}{ Perceived ease of use 3} & Experience & 5.77 & 0.85 & 1.15 & 0.25 \\
\hline & Non-experience & 5.54 & 1.11 & & \\
\hline \multirow[t]{2}{*}{ Perceived playfulness 1} & Experience & 5.90 & 0.89 & -0.63 & 0.53 \\
\hline & Non-experience & 6.02 & 0.96 & & \\
\hline \multirow[t]{2}{*}{ Perceived playfulness 2} & Experience & 5.92 & 0.86 & -0.07 & 0.94 \\
\hline & Non-experience & 5.94 & 1.16 & & \\
\hline \multirow[t]{2}{*}{ Perceived playfulness 3} & Experience & 5.63 & 1.10 & -0.14 & 0.89 \\
\hline & Non-experience & 5.67 & 1.24 & & \\
\hline \multirow[t]{2}{*}{ Subjective norm 1} & Experience & 5.38 & 1.07 & -0.63 & 0.53 \\
\hline & Non-experience & 5.52 & 1.09 & & \\
\hline \multirow[t]{2}{*}{ Subjective norm 2} & Experience & 5.19 & 1.16 & -1.38 & 0.17 \\
\hline & Non-experience & 5.50 & 1.07 & & \\
\hline \multirow[t]{2}{*}{ Image 1} & Experience & 5.33 & 1.40 & -3.07 & 0.00 \\
\hline & Non-experience & 6.02 & 0.81 & & \\
\hline \multirow[t]{2}{*}{ Image 2} & Experience & 5.58 & 1.16 & -1.94 & 0.06 \\
\hline & Non-experience & 5.98 & 0.91 & & \\
\hline \multirow[t]{2}{*}{ Output quality 1} & Experience & 5.85 & 0.85 & -0.05 & 0.96 \\
\hline & Non-experience & 5.85 & 0.95 & & \\
\hline \multirow[t]{2}{*}{ Output quality 2} & Experience & 5.83 & 0.83 & 0.31 & 0.75 \\
\hline & Non-experience & 5.77 & 0.95 & & \\
\hline \multirow[t]{2}{*}{ Usage behavior } & Experience & 6.06 & 0.75 & -0.22 & 0.82 \\
\hline & Non-experience & 6.09 & 0.86 & & \\
\hline Intention to use & Experience & 5.47 & 1.11 & -0.96 & 0.34 \\
\hline & Non-experience & 5.67 & 1.01 & & \\
\hline Perceived usefulness & Experience & 5.33 & 1.16 & -1.65 & 0.10 \\
\hline
\end{tabular}


Table 1. (Continued)

\begin{tabular}{|c|c|c|c|c|c|}
\hline Variable & Experience in using computer & Mean & S.D. & t-value & Significant value \\
\hline & Non-experience & 5.70 & 1.03 & & \\
\hline \multirow[t]{2}{*}{ Perceived ease of use } & Experience & 5.77 & 0.80 & 2.03 & 0.05 \\
\hline & Non-experience & 5.38 & 1.07 & & \\
\hline \multirow[t]{2}{*}{ perceived playfulness } & Experience & 5.82 & 0.83 & -0.30 & 0.77 \\
\hline & Non-experience & 5.88 & 1.01 & & \\
\hline \multirow[t]{2}{*}{ Subjective norm } & Experience & 5.29 & 1.08 & -1.06 & 0.29 \\
\hline & Non-experience & 5.51 & 1.01 & & \\
\hline \multirow[t]{2}{*}{ Image } & Experience & 5.45 & 1.21 & -2.72 & 0.01 \\
\hline & Non-experience & 6.00 & 0.78 & & \\
\hline \multirow[t]{2}{*}{ Output quality } & Experience & 5.84 & 0.78 & 0.14 & 0.89 \\
\hline & Non-experience & 5.81 & 0.91 & & \\
\hline
\end{tabular}

https://doi.org/10.1371/journal.pone.0200185.t001

construct. Sufficient convergent validity requires that the average variance extracted (AVE) of latent variables be no less than 0.5 and the latent variable composite reliability (CR) value be greater than 0.7. Both types of exergames' AVE values are higher than the threshold value of 0.5 , and the latent variable composite reliability values are higher than 0.7 , indicating that each construct in the measurement tool has good convergent validity. Furthermore, a measurement model should be capable of providing discriminant validity, where the square root of the AVE of the potential change items must be greater than the correlation coefficient of the other dimensions. The results showed that the square root of the average change in the latent variables was greater than the correlation coefficient of the other dimensions, thus confirming good discriminant validity of the constructs used in this study, as seen in Table 5 and Table 6. In summary, the measurement model tests, including convergent validity and discriminant validity, were satisfactory.

In terms of the fitness measures of the measurement model, Hair [40] indicated that seven common fitness measures were used to test the measurement model fit, including chi-square/ degree of freedom (X2/df), goodness-of-fit index (GFI), adjusted goodness-of-fit index (AGFI), normalized fit index (NFI), non-normalized fit index (NNFI), comparative fit index (CFI), and root mean square error of approximation (RESEA). In terms of the fitness of the measurement model for physical exergames, with the exception of the AGFI value of 0.72 , which is lower than the threshold value of 0.8 , the rest of the indexes meet satisfy the threshold, as shown in Table 7. For the cognitive exergames, GFI, AGFI, and RMSEA failed to meet the threshold value, while the rest of the indexes satisfied the threshold. Based on the result, the fitness measures of the measurement model for physical exergames were better than those for cognitive exergames, as shown in Table 7. We assume this was because the sample size associated with the physical exergames was larger than that associated with the cognitive exergames, which might have affected the result of the fitness measures for the measurement models.

\section{Structural model}

The hypotheses underlying the conceptual framework of the study were tested using a structural equation model. The path coefficients and statistics of the 12 hypotheses are shown in Fig 6 and Table 8 for the physical exergames and Fig 7 and Table 9 for the cognitive exergames.

\section{Discussion}

According to the t-test results as shown in Table 1 and Table 2, although there were a few significant differences on different computer experiences older adults' response to the 
Table 2. t-test on cognitive exergames between experienced and non-experienced computer users on the questionnaire items and variables.

\begin{tabular}{|c|c|c|c|c|c|}
\hline Variable & Experience in using computer & Mean & S.D. & t-value & Significant value \\
\hline \multirow[t]{2}{*}{ Usage behavior 1} & Experience & 5.26 & 1.50 & -0.89 & 0.38 \\
\hline & Non-experience & 5.53 & 0.97 & & \\
\hline \multirow[t]{2}{*}{ Usage behavior 2} & Experience & 5.43 & 1.24 & -0.02 & 0.99 \\
\hline & Non-experience & 5.43 & 1.19 & & \\
\hline \multirow[t]{2}{*}{ Intention to use 1} & Experience & 5.09 & 1.58 & -1.04 & 0.30 \\
\hline & Non-experience & 5.43 & 1.10 & & \\
\hline \multirow[t]{2}{*}{ Intention to use 2} & Experience & 4.63 & 1.72 & -1.61 & 0.11 \\
\hline & Non-experience & 5.27 & 1.44 & & \\
\hline \multirow[t]{2}{*}{ Intention to use 3} & Experience & 4.29 & 1.56 & -0.57 & 0.57 \\
\hline & Non-experience & 4.50 & 1.48 & & \\
\hline \multirow[t]{2}{*}{ Perceived usefulness 1} & Experience & 4.51 & 1.54 & -0.14 & 0.89 \\
\hline & Non-experience & 4.57 & 1.46 & & \\
\hline \multirow[t]{2}{*}{ Perceived usefulness 2} & Experience & 5.17 & 1.58 & -0.43 & 0.67 \\
\hline & Non-experience & 5.33 & 1.40 & & \\
\hline \multirow[t]{2}{*}{ Perceived usefulness 3} & Experience & 5.34 & 1.31 & -1.44 & 0.16 \\
\hline & Non-experience & 5.73 & 0.87 & & \\
\hline \multirow[t]{2}{*}{ Perceived usefulness 4} & Experience & 5.23 & 1.44 & -0.62 & 0.54 \\
\hline & Non-experience & 5.43 & 1.17 & & \\
\hline \multirow[t]{2}{*}{ Perceived ease of use 1} & Experience & 5.26 & 1.20 & 1.53 & 0.13 \\
\hline & Non-experience & 4.70 & 1.66 & & \\
\hline \multirow[t]{2}{*}{ Perceived ease of use 2} & Experience & 5.40 & 1.09 & 0.38 & 0.71 \\
\hline & Non-experience & 5.27 & 1.66 & & \\
\hline \multirow[t]{2}{*}{ Perceived ease of use 3} & Experience & 5.34 & 1.19 & 0.51 & 0.61 \\
\hline & Non-experience & 5.17 & 1.58 & & \\
\hline \multirow[t]{2}{*}{ Perceived playfulness 1} & Experience & 5.14 & 1.54 & -1.30 & 0.20 \\
\hline & Non-experience & 5.60 & 1.25 & & \\
\hline \multirow[t]{2}{*}{ Perceived playfulness 2} & Experience & 5.63 & 1.19 & -0.37 & 0.72 \\
\hline & Non-experience & 5.73 & 1.11 & & \\
\hline \multirow[t]{2}{*}{ Perceived playfulness 3} & Experience & 5.11 & 1.64 & -1.26 & 0.21 \\
\hline & Non-experience & 5.57 & 1.17 & & \\
\hline \multirow[t]{2}{*}{ Subjective norm 1} & Experience & 4.89 & 1.43 & -0.47 & 0.64 \\
\hline & Non-experience & 5.03 & 1.07 & & \\
\hline \multirow[t]{2}{*}{ Subjective norm 2} & Experience & 4.86 & 1.38 & -0.03 & 0.97 \\
\hline & Non-experience & 4.87 & 0.97 & & \\
\hline \multirow[t]{2}{*}{ Image 1} & Experience & 5.34 & 1.31 & -0.83 & 0.41 \\
\hline & Non-experience & 5.60 & 1.16 & & \\
\hline \multirow[t]{2}{*}{ Image 2} & Experience & 5.43 & 1.24 & -0.71 & 0.48 \\
\hline & Non-experience & 5.63 & 1.07 & & \\
\hline \multirow[t]{2}{*}{ Output quality 1} & Experience & 5.60 & 1.04 & 0.40 & 0.69 \\
\hline & Non-experience & 5.50 & 0.97 & & \\
\hline \multirow[t]{2}{*}{ Output quality 2} & Experience & 5.37 & 1.29 & -0.09 & 0.93 \\
\hline & Non-experience & 5.40 & 1.25 & & \\
\hline \multirow[t]{2}{*}{ Usage behavior } & Experience & 5.34 & 1.29 & -0.49 & 0.63 \\
\hline & Non-experience & 5.48 & 0.98 & & \\
\hline Intention to use & Experience & 4.67 & 1.50 & -1.18 & 0.24 \\
\hline & Non-experience & 5.07 & 1.20 & & \\
\hline Perceived usefulness & Experience & 5.06 & 1.31 & -0.67 & 0.50 \\
\hline
\end{tabular}


Table 2. (Continued)

\begin{tabular}{|c|c|c|c|c|c|}
\hline Variable & Experience in using computer & Mean & S.D. & t-value & Significant value \\
\hline & Non-experience & 5.27 & 1.07 & & \\
\hline \multirow[t]{2}{*}{ Perceived ease of use } & Experience & 5.33 & 1.08 & 0.93 & 0.36 \\
\hline & Non-experience & 5.04 & 1.43 & & \\
\hline \multirow[t]{2}{*}{ perceived playfulness } & Experience & 5.30 & 1.28 & -1.13 & 0.27 \\
\hline & Non-experience & 5.63 & 1.12 & & \\
\hline \multirow[t]{2}{*}{ Subjective norm } & Experience & 4.87 & 1.38 & -0.27 & 0.79 \\
\hline & Non-experience & 4.95 & 0.94 & & \\
\hline \multirow[t]{2}{*}{ Image } & Experience & 5.39 & 1.25 & -0.79 & 0.43 \\
\hline & Non-experience & 5.62 & 1.08 & & \\
\hline \multirow[t]{2}{*}{ Output quality } & Experience & 5.49 & 1.05 & 0.14 & 0.89 \\
\hline & Non-experience & 5.45 & 0.99 & & \\
\hline
\end{tabular}

https://doi.org/10.1371/journal.pone.0200185.t002

questionnaire on physical exergames, the mean values differences were less than one (e.g. the mean value for experience and non-experience participants on perceived usefulness 1 were respectively 5.08 and 5.58). Furthermore, there were no significant differences on the questionnaire responses on cognitive exergames. Hence, we believed that computer experiences will not affect the SEM results of the study. van Diest and colleagues [9] reported the study of system review in exergames for balance training of elderly and found that exergames held interesting opportunities for improvement of balance in those elderly with higher motivation and enjoyment. Anderson-Hanley and colleagues [45] also found that an exergame of cyber cycling for the elderly achieved better cognitive function than did traditional exercise.

Table 3. Reliability and validity of measurement model for physical exergames.

\begin{tabular}{|c|c|c|c|c|c|c|}
\hline Variable & Item & $\begin{array}{c}\text { Item reliability } \\
\text { (Cronbach's } \alpha \text { value) }\end{array}$ & Factor loading & Composite reliability & Average variance extracted & Item-Total Correlation \\
\hline \multirow[t]{2}{*}{ Intention to use } & IU1 & 0.9419 & 0.930 & 0.855 & 0.749 & 0.926 \\
\hline & IU2 & 0.9424 & 0.790 & & & 0.937 \\
\hline \multirow[t]{3}{*}{ Usage behavior } & UB1 & 0.9397 & 0.910 & 0.902 & 0.755 & 0.918 \\
\hline & UB2 & 0.9395 & 0.880 & & & 0.908 \\
\hline & UB3 & 0.9403 & 0.820 & & & 0.911 \\
\hline \multirow[t]{4}{*}{ Perceived usefulness } & PU1 & 0.9437 & 0.510 & 0.876 & 0.649 & 0.680 \\
\hline & PU2 & 0.9399 & 0.850 & & & 0.879 \\
\hline & PU3 & 0.9401 & 0.840 & & & 0.861 \\
\hline & PU4 & 0.9381 & 0.950 & & & 0.923 \\
\hline \multirow[t]{3}{*}{ Perceived ease of use } & EOU1 & 0.9495 & 0.550 & 0.826 & 0.624 & 0.822 \\
\hline & EOU2 & 0.9472 & 0.830 & & & 0.839 \\
\hline & EOU3 & 0.9466 & 0.940 & & & 0.871 \\
\hline \multirow[t]{3}{*}{ Perceived Playfulness } & PP1 & 0.94 & 0.890 & 0.880 & 0.710 & 0.902 \\
\hline & PP2 & 0.9396 & 0.880 & & & 0.901 \\
\hline & PP3 & 0.9416 & 0.750 & & & 0.871 \\
\hline \multirow[t]{2}{*}{ Subjective norm } & SN1 & 0.9419 & 0.880 & 0.907 & 0.830 & 0.953 \\
\hline & $\mathrm{SN} 2$ & 0.9413 & 0.940 & & & 0.957 \\
\hline \multirow[t]{2}{*}{ Image } & I1 & 0.9423 & 0.800 & 0.857 & 0.751 & 0.942 \\
\hline & $\mathrm{I} 2$ & 0.9399 & 0.930 & & & 0.926 \\
\hline \multirow[t]{2}{*}{ Output quality } & OP1 & 0.9411 & 0.890 & 0.885 & 0.794 & 0.947 \\
\hline & OP2 & 0.9406 & 0.890 & & & 0.947 \\
\hline
\end{tabular}

https://doi.org/10.1371/journal.pone.0200185.t003 
Table 4. Reliability and validity of measurement model for cognitive exergames.

\begin{tabular}{|c|c|c|c|c|c|c|}
\hline Variable & Item & $\begin{array}{c}\text { Item reliability } \\
\text { (Cronbach's } \alpha \text { value) }\end{array}$ & Factor loading & Composite reliability & Average variance extracted & Item-Total Correlation \\
\hline \multirow[t]{2}{*}{ Intention to use } & IU1 & 0.9517 & 0.800 & 0.827 & 0.706 & 0.925 \\
\hline & IU2 & 0.9498 & 0.880 & & & 0.919 \\
\hline \multirow[t]{3}{*}{ Usage behavior } & UB1 & 0.9501 & 0.870 & 0.898 & 0.747 & 0.890 \\
\hline & UB2 & 0.9499 & 0.910 & & & 0.942 \\
\hline & UB3 & 0.9508 & 0.810 & & & 0.899 \\
\hline \multirow[t]{4}{*}{ Perceived usefulness } & PU1 & 0.9511 & 0.720 & 0.913 & 0.778 & 0.847 \\
\hline & PU2 & 0.9499 & 0.900 & & & 0.914 \\
\hline & PU3 & 0.9509 & 0.800 & & & 0.854 \\
\hline & PU4 & 0.949 & 0.950 & & & 0.928 \\
\hline \multirow[t]{3}{*}{ Perceived ease of use } & EOU1 & 0.9579 & 0.690 & 0.886 & 0.726 & 0.852 \\
\hline & EOU2 & 0.9553 & 0.980 & & & 0.932 \\
\hline & EOU3 & 0.9545 & 0.860 & & & 0.910 \\
\hline \multirow[t]{3}{*}{ Perceived Playfulness } & PP1 & 0.9497 & 0.930 & 0.898 & 0.690 & 0.945 \\
\hline & PP2 & 0.9498 & 0.910 & & & 0.898 \\
\hline & PP3 & 0.9517 & 0.740 & & & 0.873 \\
\hline \multirow[t]{2}{*}{ Subjective norm } & SN1 & 0.952 & 0.920 & 0.924 & 0.859 & 0.967 \\
\hline & SN2 & 0.9522 & 0.930 & & & 0.963 \\
\hline \multirow[t]{2}{*}{ Image } & $\mathrm{I} 1$ & 0.9514 & 0.930 & 0.961 & 0.925 & 0.981 \\
\hline & $\mathrm{I} 2$ & 0.9508 & 0.990 & & & 0.979 \\
\hline \multirow[t]{2}{*}{ Output quality } & OP1 & 0.952 & 0.750 & 0.776 & 0.635 & 0.882 \\
\hline & OP2 & 0.9509 & 0.840 & & & 0.921 \\
\hline
\end{tabular}

https://doi.org/10.1371/journal.pone.0200185.t004

This set of exergames was designed to create a space with physical and cognitive exercise through art and technology in social interaction for the health promotion of the elderly. In designing the exergames, it was speculated that different types of games may result in differing degrees of acceptance and impact among the elderly. Accordingly, as described above, two specific types of games were designed, i.e., physical games ("Interactive Wall with Life Memories,"

Table 5. Discriminant validity of the latent constructs for physical exergames.

\begin{tabular}{l|c|c|c|c|c|c|c|c}
\hline & Perceived ease of use & Image & $\begin{array}{c}\text { Intention } \\
\text { to use }\end{array}$ & Output quality & Perceived playfulness & Perceived usefulness & Subjective norm & Usage behavior \\
\hline $\begin{array}{l}\text { Perceived } \\
\text { ease of use }\end{array}$ & $\mathbf{0 . 8 4 6}$ & & & & & & \\
\hline Image & .195 & $\mathbf{0 . 9 3 1}$ & & & & & \\
\hline Intention to use & .225 & .455 & $\mathbf{0 . 9 3 1}$ & & & & \\
\hline Output quality & .267 & .666 & .577 & $\mathbf{0 . 9 4 6}$ & & & \\
\hline $\begin{array}{l}\text { Perceived } \\
\text { Playfulness }\end{array}$ & .245 & .598 & .714 & .748 & $\mathbf{0 . 8 9 2}$ & & \\
\hline Perceived usefulness & .171 & .743 & .630 & .701 & .777 & & \\
\hline Subjective norm & .141 & .661 & .360 & .626 & .603 & .849 & \\
\hline Usage behavior & .196 & .678 & .706 & .620 & .799 & .820 & \\
\hline
\end{tabular}

Note: The diagonals represent the average variance extracted (AVE), while the other matrix entries represent the shared variance (the squared correlations).

${ }^{* *} \mathrm{P}<0.01$

${ }^{*} \mathrm{P}<0.05$.

https://doi.org/10.1371/journal.pone.0200185.t005 
Table 6. Discriminant validity of the latent constructs for cognitive exergames.

\begin{tabular}{|c|c|c|c|c|c|c|c|c|}
\hline & $\begin{array}{c}\text { Perceived ease of } \\
\text { use }\end{array}$ & $\begin{array}{c}\text { Intention to } \\
\text { use }\end{array}$ & Image & $\begin{array}{l}\text { Output } \\
\text { quality }\end{array}$ & $\begin{array}{c}\text { Perceived } \\
\text { Playfulness }\end{array}$ & $\begin{array}{l}\text { Perceived } \\
\text { usefulness }\end{array}$ & $\begin{array}{c}\text { Subjective } \\
\text { norm }\end{array}$ & $\begin{array}{c}\text { Usage } \\
\text { behavior }\end{array}$ \\
\hline $\begin{array}{l}\text { Perceived } \\
\text { ease of use }\end{array}$ & 0.893 & & & & & & & \\
\hline Intention to use & .292 & 0.921 & & & & & & \\
\hline Image & .224 & .528 & 0.979 & & & & & \\
\hline Output quality & .402 & .735 & .657 & 0.899 & & & & \\
\hline $\begin{array}{l}\text { Perceived } \\
\text { Playfulness }\end{array}$ & .307 & .859 & .586 & .726 & 0.905 & & & \\
\hline $\begin{array}{l}\text { Perceived } \\
\text { usefulness }\end{array}$ & .282 & .815 & .768 & .673 & .806 & 0.886 & & \\
\hline Subjective norm & .367 & .382 & .690 & .562 & .563 & .545 & 0.964 & \\
\hline Usage behavior & .260 & .770 & .639 & .611 & .805 & .863 & .541 & 0.911 \\
\hline
\end{tabular}

Note: The diagonals represent the average variance extracted (AVE), while the other matrix entries represent the shared variance (the squared correlations).

** $\mathrm{P}<0.01$

${ }^{*} \mathrm{P}<0.05$.

https://doi.org/10.1371/journal.pone.0200185.t006

"Interactive Floor Kick and Play," and "Ten Pretty Passes of the Bull") and cognitive exergames ("Interactive Table with Musical Pots" and "Fun Cube").

For both types of exergames, the path analysis results revealed the existence of a significant relationship between the output quality variable and the perceived playfulness variable. In other words, it appears that if users are satisfied with the exergame interface and its appearance, they find the exergame more interesting and enjoyable. This inference is consistent with that reported by Koufaris [25], that the user enjoyment experienced when using a particular website is directly related to the quality of the information and services which it provides. However, a relationship between the output quality variable and the usage behavior variable was found only in the case of the cognitive exergames. This suggests that cognitive exergames require the user to focus more carefully on the game interface in order to acquire the information needed to play the games and achieve task completion. In other words, interface design is more important for cognitive exergames than for physical exergames.

For both types of exergames, both the perceived playfulness and perceived usefulness variables were both related to the intention and usage behavior variables. In other words, it appears that when users both enjoys playing an exergame and recognizes its health benefits, they cultivate a more positive attitude toward the game, which is reflected in a greater intention to use the game and a more proactive usage behavior. This result is consistent with that of Moon and Kim [29]. The findings regarding the perceived usefulness variable are also

Table 7. Fit indexes for the measurement model of both types of exergames.

\begin{tabular}{c|c|c|c|c}
\hline Measures & Recommended criteria & Suggested by authors & Physical exergames & Cognitive exergames \\
\hline$\chi 2 / \mathrm{df}$ & $<3.0$ & Bentler [41] & 1.733 & 2.236 \\
\hline GFI & $>0.8$ & Seyal [42] & 0.810 & 0.690 \\
\hline AGFI & $>0.8$ & Scott [43] & 0.720 & 0.550 \\
\hline NFI & $>0.9$ & Hair Jr [40] & 0.950 & 0.910 \\
\hline NNFI & $>0.9$ & Hair Jr [40] & 0.970 & 0.930 \\
\hline CFI & $>0.9$ & Bagozzi [44] & 0.980 & 0.950 \\
\hline RMSEA & $<0.08$ & Bagozzi [44] & 0.075 & 0.120 \\
\hline
\end{tabular}

https://doi.org/10.1371/journal.pone.0200185.t007 


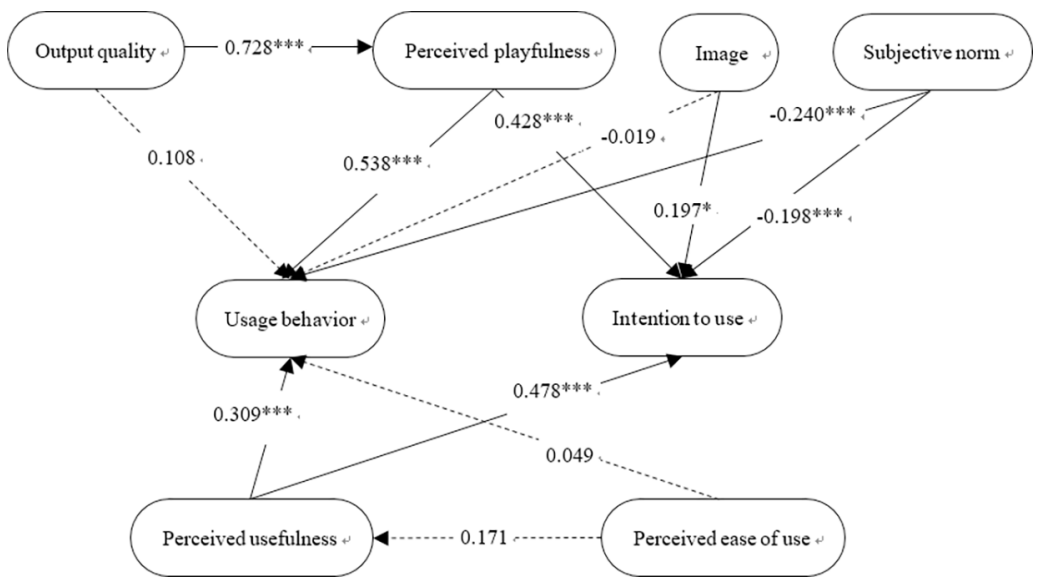

Fig 6. Path analysis model for research hypotheses pertaining to physical exergames.

https://doi.org/10.1371/journal.pone.0200185.g006

consistent with those presented in [26, 32], which show that when users perceive an e-commerce website to have a higher usefulness, they are more likely to have a positive attitude toward accessing the site and to reusing it in the future.

A positive relationship was not found between the perceived ease of use variable and the usage behavior variable in either type of exergame. Furthermore, a relationship between the perceived ease of use and the perceived usefulness was found only for the cognitive exergames. This somewhat surprising result may stem from users in this study having only limited prior experience in using computer technology. For example, nearly half of the users (16 people) reported that they had never used a computer before. As a result, the exergames represent a very new experience for many of them, and it seems that this affects both the perceived usefulness of the games and the behavior of the users when actually playing the physical exergames.

For the physical exergames, the image and subjective norm variables were both found to affect the users' intention to use. Furthermore, the subjective norm variable also affected their

Table 8. TAM2 analysis of research hypotheses pertaining to physical exergames.

\begin{tabular}{|c|c|c|c|c|c|c|}
\hline Extrinsic variables & $\rightarrow$ & Intrinsic variables & Regression coefficients & t-value & Significance & $\begin{array}{c}\text { Path } \\
\text { analysis }\end{array}$ \\
\hline H1.Output quality & $\rightarrow$ & Perceived playfulness & 0.728 & 9.20 & $* * *$ & Supported \\
\hline H2.Output quality & $\rightarrow$ & Usage behavior & 0.108 & 0.53 & 0.597 & Not supported \\
\hline H3. Perceived playfulness & $\rightarrow$ & Intention to use & 0.428 & 6.24 & $* * *$ & Supported \\
\hline H4. Perceived playfulness & $\rightarrow$ & Usage behavior & 0.538 & 4.18 & $* * *$ & Supported \\
\hline H5. Perceived usefulness & $\rightarrow$ & Usage behavior & 0.309 & 3.52 & $* * *$ & Supported \\
\hline H6. Perceived usefulness & $\rightarrow$ & Intention to use & 0.478 & 4.77 & $* * *$ & Supported \\
\hline H7. Perceived ease of use & $\rightarrow$ & Perceived usefulness & 0.171 & 1.92 & 0.057 & Not supported \\
\hline H8. Perceived ease of use & $\rightarrow$ & Usage behavior & 0.049 & 0.25 & 0.803 & Not supported \\
\hline H9. Image & $\rightarrow$ & Usage behavior & -0.019 & -0.04 & 0.968 & Not supported \\
\hline H10. Image & $\rightarrow$ & Intention to use & 0.197 & 2.01 & $*$ & Supported \\
\hline H11. Subjective norm & $\rightarrow$ & Usage behavior & -0.240 & -3.34 & $* * *$ & Supported \\
\hline H12.Subjective norm & $\rightarrow$ & Intention to use & -0.198 & -3.42 & $* * *$ & Supported \\
\hline \multicolumn{7}{|l|}{$* * * \mathrm{p}<0.001$} \\
\hline \multicolumn{7}{|l|}{${ }^{* *} \mathrm{p}<0.01$} \\
\hline${ }^{*} \mathrm{p}<0.05$ & & & & & & \\
\hline
\end{tabular}

https://doi.org/10.1371/journal.pone.0200185.t008 


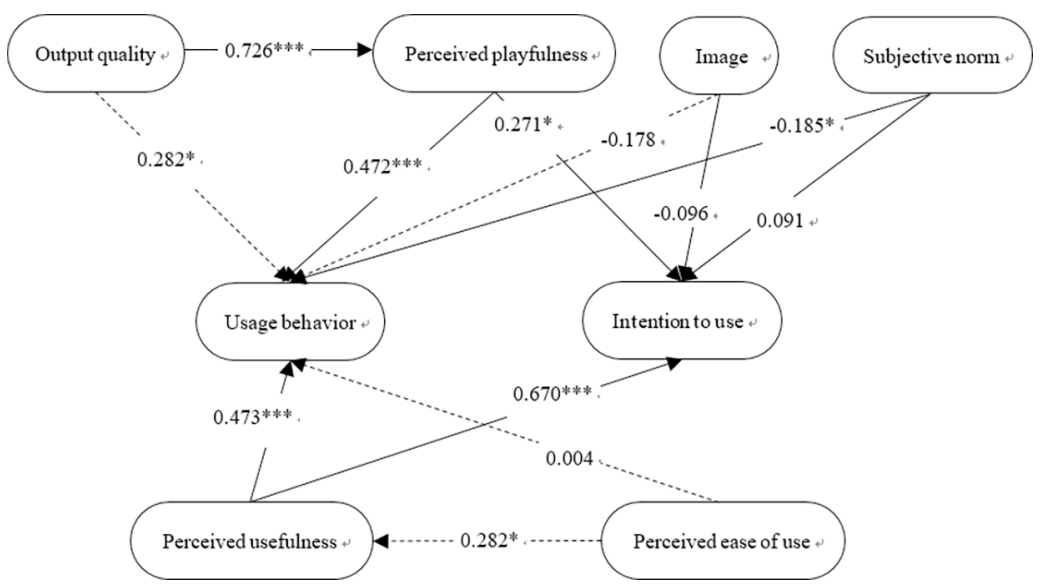

Fig 7. Path analysis model for research hypotheses pertaining to cognitive exergames.

https://doi.org/10.1371/journal.pone.0200185.g007

usage behavior. In other words, the physical exergames encourage the users to focus on their health and promote a willingness to play them. Moreover, the use of a physical exergame by peers and friends also influences their willingness to use the game and enhances their positive feelings toward it. For cognitive exergames, the subjective norm again influences the user's usage behavior. However, no significant relationships were found between the subjective norm and the intention to use variables, or between the image variable and the usage behavior or intention to use variables.

Overall, the results of this study show that perceived playfulness is significantly related to the usage behavior and intention to use of elderly users for both physical and cognitive exergames. In addition, the output quality of the game affects the perceived playfulness and usage behavior of the elderly for both types of games. As for the social influence effect on the usage behavior and intention to use characteristics of elderly users, it appears that when the games are played in a public space and involve obvious physical movement, they attract the attention

Table 9. TAM2 analysis of research hypotheses pertaining to cognitive exergames.

\begin{tabular}{|c|c|c|c|c|c|c|}
\hline Extrinsic variables & $\rightarrow$ & Intrinsic variables & Regression coefficients & t-value & Significance & $\begin{array}{c}\text { Path } \\
\text { analysis }\end{array}$ \\
\hline H1.Output quality & $\rightarrow$ & Perceived playfulness & 0.726 & 9.76 & $* * *$ & Supported \\
\hline H2.Output quality & $\rightarrow$ & Usage behavior & 0.282 & 2.62 & $*$ & Supported \\
\hline H3. Perceived playfulness & $\rightarrow$ & Intention to use & 0.271 & 1.99 & $*$ & Supported \\
\hline H4. Perceived playfulness & $\rightarrow$ & Usage behavior & 0.472 & 3.95 & $* * *$ & Supported \\
\hline H5. Perceived usefulness & $\rightarrow$ & Usage behavior & 0.473 & 3.79 & $* * *$ & Supported \\
\hline H6. Perceived usefulness & $\rightarrow$ & Intention to use & 0.670 & 4.53 & $* * *$ & Supported \\
\hline H7. Perceived ease of use & $\rightarrow$ & Perceived usefulness & 0.282 & 2.33 & $*$ & Supported \\
\hline H8. Perceived ease of use & $\rightarrow$ & Usage behavior & 0.004 & 0.05 & 0.960 & Not supported \\
\hline H9. Image & $\rightarrow$ & Usage behavior & -0.178 & -1.70 & 0.090 & Not supported \\
\hline H10. Image & $\rightarrow$ & Intention to use & -0.096 & 0.84 & 0.403 & Not supported \\
\hline H11. Subjective norm & $\rightarrow$ & Usage behavior & -0.185 & -2.28 & $*$ & Supported \\
\hline H12.Subjective norm & $\rightarrow$ & Intention to use & 0.091 & 0.96 & 0.340 & Not supported \\
\hline \multicolumn{7}{|l|}{${ }^{* * *} \mathrm{p}<0.001$} \\
\hline \multicolumn{7}{|l|}{${ }^{* *} \mathrm{p}<0.01$} \\
\hline${ }^{*} \mathrm{p}<0.05$ & & & & & & \\
\hline
\end{tabular}

https://doi.org/10.1371/journal.pone.0200185.t009 
of other residents in Silver Village, and hence lead to increased social interaction under the premise of health promotion. This assertion may well explain the greater acceptance of the physical exergames compared to the cognitive exergames, which are generally more static in nature.

Around half of the users in the present study reported having no previous experience in using computer technology products. Table 1 shows the t-test result of physical exergames between experienced and non-experienced computer users on the questionnaire items and variables. There were significant differences between the two groups of participants on perceived playfulness 1 , perceived playfulness 4 , perceived ease of use 1 , image 1 , image 2 , perceived ease of use, and image; there were no significant differences on rest of the questionnaire items and variables. Unlike the physical exergames, no significant differences were found between experienced and non-experienced computer users on all of the questionnaire items and variables of the cognitive exergames, as shown in Table 2 . The results suggest that this affects their perceived ease of use in playing the exergames. It may also account for the absence of any significant relationship between the perceived ease of use and the usage behavior (for both types of exergames), or the perceived ease of use and the perceived usefulness (for the physical exergames). The present results have found a generally positive relationship between the social influence aspects of physical exergames and the intention to use and usage behavior of the users. However, similar relationships were not observed for the cognitive exergames. Thus, future studies should attempt to improve the design of cognitive exergames in such a way as to attract the attention of others and foster in them an interest in trying the games for themselves.

\section{Conclusions}

The results of this study show that the perceived playfulness and perceived usefulness of physical and cognitive exergames are significantly related to the usage behavior and intention to use of elderly users. However, the output quality affects the usage behavior only in the case of cognitive exergames. In addition, social influence affects the intention to use and usage behavior of elderly users more strongly for physical exergames than for cognitive exergames. Overall, the results of this study suggest that in designing exergames for the elderly, perceived playfulness and perceived usefulness are two main factors that affect their willingness to use exergames. Designers should also bear in mind that when designing physical exergames, image and subjective norms are also two variables that could affect users' intention to play physical exergames.

\section{Supporting information}

S1 File. TAM of Interactive Wall with Life Memories_Cht. (PDF)

S2 File. TAM of Interactive Wall with Life Memories_Eng. (PDF)

S3 File. TAM of Interactive Floor Kick and Play_Cht. (PDF)

S4 File. TAM of Interactive Floor Kick and Play_Eng. (PDF)

S5 File. TAM of Ten Pretty Passes of the Bull_Cht. (PDF) 
S6 File. TAM of Ten Pretty Passes of the Bull_Eng.

(PDF)

S7 File. TAM of Interactive Table with Musical Pots_Cht.

(PDF)

S8 File. TAM of Interactive Table with Musical Pots_Eng.

(PDF)

S9 File. TAM of Fun Cube_Cht.

(PDF)

S10 File. TAM of Fun Cube_Eng.

(PDF)

S11 File. 100-1075B IRB Eng.

(PDF)

S12 File. ClinicalTrial NCT03084107.

(PDF)

S13 File. Consent form for publication.

(PDF)

\section{Author Contributions}

Conceptualization: Chung-Chih Lin, Su-Chu Hsu, Alice M. K. Wong.

Data curation: Tsai-Hsuan Tsai.

Formal analysis: Tsai-Hsuan Tsai.

Funding acquisition: Chung-Chih Lin, Chia-Ying Chung, Alice M. K. Wong.

Investigation: Chih-Kuang Chen, Yin-Chou Lin.

Methodology: Tsai-Hsuan Tsai.

Project administration: Chia-Ying Chung.

Resources: Su-Chu Hsu.

Software: Chung-Chih Lin.

Supervision: Yu-Cheng Pei.

Validation: Yin-Chou Lin.

Visualization: Su-Chu Hsu.

Writing - original draft: Chih-Kuang Chen.

Writing - review \& editing: Alice M. K. Wong.

\section{References}

1. Engel GL. The biopsychosocial model in medical education. The New England journal of medicine. 1982; 307(12):760-1. https://doi.org/10.1056/NEJM198209163071225 PMID: 7110237.

2. Fox KR, Hillsdon M. Physical activity and obesity. Obesity reviews: an official journal of the International Association for the Study of Obesity. 2007; 8 Suppl 1:115-21. https://doi.org/10.1111/j.1467-789X. 2007.00329.x PMID: 17316313. 
3. Etnier JL, Nowell P M, Landers DM, Sibley BA. A meta-regression to examine the relationship between aerobic fitness and cognitive performance. Brain Research Reviews. 2006; 52(1):119-30. https://doi. org/10.1016/j.brainresrev.2006.01.002 PMID: 16490256

4. Colcombe S, Kramer AF. Fitness effects on the cognitive function of older adults: a meta-analytic study. Psychological science. 2003; 14(2):125-30. https://doi.org/10.1111/1467-9280.t01-1-01430 PMID: 12661673.

5. Schutzer KA, Graves BS. Barriers and motivations to exercise in older adults. Preventive medicine. 2004; 39(5):1056-61. https://doi.org/10.1016/j.ypmed.2004.04.003 PMID: 15475041.

6. Theng Y-L, Dahlan AB, Akmal ML, Myint TZ. An exploratory study on senior citizens' perceptions of the Nintendo Wii: the case of Singapore. Proceedings of the 3rd International Convention on Rehabilitation Engineering \\& Assistive Technology; Singapore. 1592712: ACM; 2009. p. 1-5.

7. Bieryla KA, Dold NM. Feasibility of Wii Fit training to improve clinical measures of balance in older adults. Clin Interv Aging. 2013; 8:775-81. Epub 2013/07/10. https://doi.org/10.2147/CIA.S46164 PMID: 23836967; PubMed Central PMCID: PMCPMC3699053.

8. Fu AS, Gao KL, Tung AK, Tsang WW, Kwan MM. Effectiveness of Exergaming Training in Reducing Risk and Incidence of Falls in Frail Older Adults With a History of Falls. Archives of physical medicine and rehabilitation. 2015; 96(12):2096-102. https://doi.org/10.1016/j.apmr.2015.08.427 PMID: 26360975.

9. van Diest M, Lamoth CJ, Stegenga J, Verkerke GJ, Postema K. Exergaming for balance training of elderly: state of the art and future developments. J Neuroeng Rehabil. 2013; 10:101. Epub 2013/09/26. https://doi.org/10.1186/1743-0003-10-101 PMID: 24063521; PubMed Central PMCID: PMCPMC3851268.

10. Whitlock LA, McLaughlin AC, Allaire JC. Video Game Design for Older Adults Usability Observations from an Intervention Study. Proceedings of the Human Factors and Ergonomics Society Annual Meeting2011. p. 187-91.

11. Gao Y, Mandryk R. The acute cognitive benefits of casual exergame play. Proceedings of the SIGCHI Conference on Human Factors in Computing Systems; Austin, Texas, USA. 2208323: ACM; 2012. p. 1863-72.

12. Harris DM, Rantalainen T, Muthalib M, Johnson L, Teo W- P. Exergaming as a viable therapeutic tool to improve static and dynamic balance among older adults and people with idiopathic Parkinson's disease: a systematic review and meta-analysis. Frontiers in Aging Neuroscience. 2015; 7. https://doi.org/10. 3389/fnagi.2015.00167 PMID: 26441634

13. Verheijden Klompstra L, Jaarsma $T$, Strömberg A. Exergaming in older adults: A scoping review and implementation potential for patients with heart failure. European Journal of Cardiovascular Nursing. 2014; 13(5):388-98. https://doi.org/10.1177/1474515113512203 PubMed PMID: PMC4361694. PMID: 24198306

14. Davis FD, Bagozzi RP, Warshaw PR. User acceptance of computer technology: a comparison of two theoretical models. Manage Sci. 1989; 35(8):982-1003. https://doi.org/10.1287/mnsc.35.8.982

15. Venkatesh V, Davis FD. A Theoretical Extension of the Technology Acceptance Model: Four Longitudinal Field Studies. Manage Sci. 2000; 46(2):186-204. https://doi.org/10.1287/mnsc.46.2.186.11926

16. Venkatesh V, Morris MG, Davis GB, Davis FD. User acceptance of information technology: toward a unified view. MIS Q. 2003; 27(3):425-78.

17. Venkatesh $\mathrm{V}$, Bala $\mathrm{H}$. Technology Acceptance Model 3 and a Research Agenda on Interventions. Decision Sciences. 2008; 39(2):273-315. https://doi.org/10.1111/j.1540-5915.2008.00192.x

18. Tsai $\mathrm{T}-\mathrm{H}$, Chang $\mathrm{H}-\mathrm{T}$, Wong $\mathrm{AM}-\mathrm{K}$, Wu T-F, editors. Connecting communities: designing a social media platform for older adults living in a senior village. International Conference on Universal Access in Human-Computer Interaction; 2011: Springer.

19. Xue L, Yen CC, Chang L, Chan HC, Tai BC, Tan SB, et al. An exploratory study of ageing women's perception on access to health informatics via a mobile phone-based intervention. Int J Med Inform. 2012; 81(9):637-48. Epub 2012/06/05. https://doi.org/10.1016/j.ijmedinf.2012.04.008 PMID: 22658778.

20. Wong AM, Chang WH, Ke PC, Huang CK, Tsai TH, Chang HT, et al. Technology acceptance for an Intelligent Comprehensive Interactive Care (ICIC) system for care of the elderly: a survey-questionnaire study. PloS one. 2012; 7(8):e40591. Epub 2012/08/08. https://doi.org/10.1371/journal.pone.0040591 PMID: 22870200; PubMed Central PMCID: PMCPMC3411612.

21. Ramón-Jerónimo MA, Peral-Peral B, Arenas-Gaitan J. Elderly persons and Internet use. Social Science Computer Review. 2013; 31(4):389-403.

22. Wüest $S$, Borghese NA, Pirovano M, Mainetti R, van de Langenberg R, de Bruin ED. Usability and effects of an exergame-based balance training program. GAMES FOR HEALTH: Research, Development, and Clinical Applications. 2014; 3(2):106-14. 
23. Cook N, Winkler SL. Acceptance, Usability and Health Applications of Virtual Worlds by Older Adults: A Feasibility Study. JMIR Res Protoc. 2016; 5(2):e81. Epub 2016/06/04. https://doi.org/10.2196/resprot. 5423 PMID: 27256457; PubMed Central PMCID: PMCPMC4911513.

24. Ben-Sadoun G, Sacco G, Manera V, Bourgeois J, König A, Foulon P, et al. Physical and cognitive stimulation using an exergame in subjects with normal aging, mild and moderate cognitive impairment. Journal of Alzheimer's Disease. 2016; 53(4):1299-314. https://doi.org/10.3233/JAD-160268 PMID: 27372645

25. Koufaris M. Applying the Technology Acceptance Model and Flow Theory to Online Consumer Behavior. Info Sys Research. 2002; 13(2):205-23. https://doi.org/10.1287/isre.13.2.205.83

26. Ahn T, Ryu S, Han I. The impact of Web quality and playfulness on user acceptance of online retailing. Inf Manage. 2007; 44(3):263-75. https://doi.org/10.1016/j.im.2006.12.008

27. O'Cass A, Grace D. Exploring consumer experiences with a service brand. Journal of Product \& Brand Management. 2004; 13(4):257-68. https://doi.org/10.1108/10610420410546961

28. Carlson J, O'Cass A. Exploring the relationships between e-service quality, satisfaction, attitudes and behaviours in content-driven e-service web sites. Journal of Services Marketing. 2010; 24(2):112-27. https://doi.org/10.1108/08876041011031091

29. Moon J-W, Kim Y-G. Extending the TAM for a World-Wide-Web context. Inf Manage. 2001; 38(4):21730. https://doi.org/10.1016/s0378-7206(00)00061-6

30. Triandis HC. Attitude and attitude change / Harry C. Triandis. New York: John Wiley \& Sons, Inc; 1971.

31. Csikszentmihalyi M, Csikszentmihalyi I. Beyond boredom and anxiety. San Francisco: Jossey-Bass Publishers; 2000.

32. Kim H-b, Kim T, Shin SW. Modeling roles of subjective norms and eTrust in customers' acceptance of airline B2C eCommerce websites. Tourism Management. 2009; 30(2):266-77. http://dx.doi.org/10. 1016/j.tourman.2008.07.001.

33. Fishbein M, Ajzen I. Belief, attitude, intention, and behavior: an introduction to theory and research: Addison-Wesley Pub. Co.; 1975.

34. Davis FD. Perceived usefulness, perceived ease of use, and user acceptance of information technology. MIS Q. 1989; 13(3):319-40. https://doi.org/10.2307/249008

35. Herrero Crespo Á, Rodríguez Del Bosque Rodríguez IA. Explaining B2C e-commerce acceptance: An integrative model based on the framework by Gatignon and Robertson. Interacting with Computers. 2008; 20(2):212-24. http://dx.doi.org/10.1016/j.intcom.2007.11.005.

36. Lin H-F. Predicting consumer intentions to shop online: An empirical test of competing theories. Electron Commer Rec Appl. 2007; 6(4):433-42. https://doi.org/10.1016/j.elerap.2007.02.002

37. Moore GC, Benbasat I. Development of an Instrument to Measure the Perceptions of Adopting an Information Technology Innovation. Information Systems Research. 1991; 2(3):192-222. https://doi.org/10. 1287/isre.2.3.192

38. Gerling KM, Schulte FP, Masuch M. Designing and evaluating digital games for frail elderly persons. Proceedings of the 8th International Conference on Advances in Computer Entertainment Technology; Lisbon, Portugal. 2071501: ACM; 2011. p. 1-8.

39. Hair JF, Tatham RL, Anderson RE, Black W. Multivariate Data Analysis. fifth ed. London: Prentice Hall; 1998.

40. Joseph F Hair J, Anderson RE, Tatham RL. Multivariate data analysis with readings ( 2 nd ed.): Macmillan Publishing Co., Inc.; 1986.

41. Bentler PM., Bonett D. Significance Tests and Goodness-of-Fit in Analysis of Covariance Structures1980. 588-606 p.

42. Seyal $A, A$ Rahman $M N$, Rahim M. Determinants of academic use of the Internet: A structural equation model2002. 71-86 p.

43. Scott JE. The measurement of information systems effectiveness: evaluating a measuring instrument. ACM SIGMIS Database. 1995; 26(1):43-61.

44. Bagozzi RP, Yi Y. On the evaluation of structural equation models. Journal of the academy of marketing science. 1988; 16(1):74-94.

45. Anderson-Hanley C, Arciero PJ, Brickman AM, Nimon JP, Okuma N, Westen SC, et al. Exergaming and older adult cognition: a cluster randomized clinical trial. Am J Prev Med. 2012; 42(2):109-19. Epub 2012/01/21. https://doi.org/10.1016/j.amepre.2011.10.016 PMID: 22261206. 